\title{
FAM3A Protects HT22 Cells Against Hydrogen Peroxide-Induced Oxidative Stress Through Activation of PI3K/Akt but not MEK/ERK Pathway
}

\author{
Qing Song Wen-Li Gou Rong Zhang
}

Department of Obstetrics and Gynecology, the First Affiliated Hospital, Xian Jiaotong University, Xi'an, Shaanxi, China

\section{Key Words}

FAM3A • Oxidative stress $\cdot$ Mitochondria $\cdot$ Akt $・$ ERK

\begin{abstract}
Background/Aims: Oxidative stress-induced cell damage is involved in many neurological diseases. FAM3A is the first member of family with sequence similarity 3 (FAM3) gene family and its biological function remains largely unknown. Methods: This study aimed to determine its role in hydrogen peroxide $\left(\mathrm{H}_{2} \mathrm{O}_{2}\right)$ induced injury in neuronal HT22 cells. The protective effects were measured by cell viability, lactate dehydrogenase (LDH) release and apoptosis, and oxidative stress was assayed by reactive oxygen species (ROS) generation, ATP synthesis and lipid peroxidation. By using selective inhibitors, the involvement of PI3K/Akt and MEK/ ERK pathways were also investigated. Results: The results of fluorescence staining revealed that $\mathrm{H}_{2} \mathrm{O}_{2}$ significantly decreased the expression of FAM3A protein, which was shown to be subcellularly located in mitochondria. Up-regulation of FAM3A by lentivirus transfection markedly increased cell viability and decreased LDH release after $\mathrm{H}_{2} \mathrm{O}_{2}$ treatment. The antiapoptotic activity of FAM3A was demonstrated by the reduced mitochondrial cytochrome $c$ release, decreased activation of caspase- 3 and the results of flow cytometry. Overexpression of FAM3A attenuated intracellular ROS generation and loss of ATP production induced by $\mathrm{H}_{2} \mathrm{O}_{2}$, and subsequently inhibited lipid peroxidation. In addition, overexpression of FAM3A significantly increased the activation of Akt and ERK in $\mathrm{H}_{2} \mathrm{O}_{2}$ injured $\mathrm{HT} 22$ cells. By using Akt and ERK specific inhibitors, we found that inhibition of PI3K/Akt, but not MEK/ERK pathway, partially prevented FAM3A-induced protection against $\mathrm{H}_{2} \mathrm{O}_{2}$. Conclusion: These results suggest that FAM3A has protective effects against $\mathrm{H}_{2} \mathrm{O}_{2}$-induced oxidative stress by reducing ROS accumulation and apoptosis, and these protective effects are dependent on the activation of PI3K/Akt pathway.

(C) 2015 The Author(s)

Published by S. Karger AG, Basel
\end{abstract}

\section{Introduction}

Reactive oxygen species (ROS), the chemically reactive molecules formed by incomplete one-electron reduction of oxygen, play important roles in cell signaling and homeostasis [1].

Dr. Qing Song

KARGER 125 


\section{Cellular Physiology Cell Physiol Biochem 2015;37:1431-1441

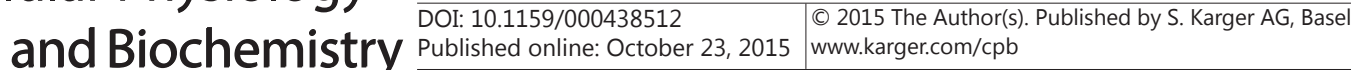 \\ Song/Gou/Zhang: FAM3A Protects $\mathrm{HT} 12$ Cells Against $\mathrm{H}_{2} \mathrm{O}_{2}$ Injury}

However, increased ROS production under aberrant metabolic processes leads to oxidative stress, which has been implicated in the pathophysiology of various neurological disorders [2-4]. It is well known that the mammalian brain has high amount of oxygen but low levels of antioxidant enzymes, making it particularly sensitive to oxidative damage $[5,6]$. The ROSinduced oxidative stress in neuronal cells triggers a mechanism that, through the release of cytochrome $\mathrm{c}$ and activation of caspase-3, leads to intrinsic apoptosis. Hydrogen peroxide $\left(\mathrm{H}_{2} \mathrm{O}_{2}\right)$, a highly reactive ROS, is thought to be the radical most responsible for oxidative neuronal damage. It has been widely used to mimic in vitro oxidative stress in many different cell types, including HT22 hippocampal neuronal cells [7, 8].

The family with sequence similarity 3 (FAM3) gene family is a cytokine-like gene family identified in 2002 with four members: FAM3A, FAM3B, FAM3C and FAM3D [9]. It is shown that FAM3B is highly expressed in pancreas, FAM3D in placenta, and FAM3A and FAM3C in almost all tissues. Increasing evidence suggests that these FAM3 family members are involved in the development and progression of many human diseases, such as diabetes and cancer [10]. Most of the studies of FAM3 family proteins are focused on FAM3B, which is also known as pancreatic-derived factor (PANDER) due to its high abundance in pancreatic islets [11]. Previous studies showed that dysregulated FAM3B could promote the pathogenesis of type 2 diabetes by decreasing pancreatic $\beta$ cell function and hepatic insulin sensitivity [12]. However, the physiological role of FAM3A remains largely unknown. FAM3A mRNA is ubiquitously expressed in almost all tissues of human and rodent, and FAM3A protein is composed of 230 amino acid residues [9]. Recent studies reported that FAM3A is a target gene of peroxisome proliferator-activated receptor $\gamma$ (PPAR $\gamma$ ) [13], and overexpression of FAM3A significantly attenuates hyperglycemia, insulin resistance and fatty liver via $\mathrm{Ca}^{2+}$ mediated activation of PI3K/Akt signaling [14].

In the present study, we reported thatFAM3A is expressed in HT22 hippocampal neuronal cells, where its expression was significantly decreased by $\mathrm{H}_{2} \mathrm{O}_{2}$ treatment. Overexpression of FAM3A markedly attenuated $\mathrm{H}_{2} \mathrm{O}_{2}$-induced cytotoxicity and apoptosis with suppressed oxidative stress in HT22 cells. These effects of FAM3A were found to be mediated by PI3K/ Akt, but not MEK/ERK signaling.

\section{Materials and Methods}

\section{Cell culture}

The neuronal HT22 cells were cultured in Dulbecco's modified Eagle's medium, supplemented with $10 \%$ fetal bovine serum (FBS) and incubated at $37^{\circ} \mathrm{C}$ with $5 \% \mathrm{CO}_{2}$, and $95 \%$ humidity.

\section{Cell viability assay}

Cell viability assay was performed using the cell proliferation reagent WST-1 following the manufacture's protocol (Roche, Basel, Switzerland). Briefly, cells were cultured at a concentration of $3 \times 10^{5}$ in microplates in a final volume of $100 \mu \mathrm{l} /$ well culture medium. After various treatments, $10 \mu \mathrm{l}$ WST-1 was added into each well and incubated for $4 \mathrm{~h}$ at $37^{\circ} \mathrm{C}$. Then, $100 \mu \mathrm{l} /$ well culture medium and $10 \mu \mathrm{l} \mathrm{WST}-1$ was added into one well in the absence of cells, and its absorbance was used as a blank position for the enzymelinked immunosorbent assay (ELISA) reader. The cells were shaken thoroughly for $1 \mathrm{~min}$ on a shaker and the absorbance of the samples was measured using a microplate reader.

Lactate dehydrogenase $(\mathrm{LDH})$ release assay

Cytotoxicity was determined by the release of LDH using a diagnostic kit according to the manufacturer's instructions. Briefly, $50 \mu \mathrm{l}$ of the supernatant from each well was incubated with the reduced form of nicotinamide-adenine dinucleotide (NADH) and pyruvate for $15 \mathrm{~min}$ at $37^{\circ} \mathrm{C}$ and the reaction was stopped by adding $0.4 \mathrm{M} \mathrm{NaOH}$. The activity of LDH was calculated from the absorbance at $440 \mathrm{~nm}$, and the background absorbance from the culture medium that was not used for any cell cultures was subtracted from all of the absorbance measurements. 


\section{Cellular Physiology Cell Physiol Biochem 2015;37:1431-1441

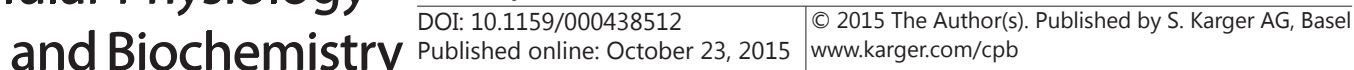 \\ Song/Gou/Zhang: FAM3A Protects HT12 Cells Against $\mathrm{H}_{2} \mathrm{O}_{2}$ Injury}

Immunocytochemistry (ICC)

HT22 cells were fixed for 30 min with 4\% paraformaldehyde, rinsed twice with PBS and subsequently incubated with blocking solution (PBS containing 1\% bovine serum albumin, $0.4 \%$ Triton X-100 and 4\% normal goat serum) for $20 \mathrm{~min}$. Next, cells were incubated with primary antibody (1:500; anti-FAM3A) at $4{ }^{\circ} \mathrm{C}$ overnight. The cells were then rinsed twice and incubated with fluorescein isothiocyanate (FITC) labeled secondary antibody (1:600; goat anti-rabbit) for $1 \mathrm{~h}$ at room temperature. Mito tracker (Red) and DAPI were used to stain mitochondria and nucleus, respectively.

\section{Lentivirus construction and transfection}

The coding sequence of FAM3A was amplified by RT-PCR with sequences: forward, 5'-TCA TGA GCA GCG TCA AAGAC-3'; reverse, 5'-AGG GTA CCT TCA TGC AGTGG-3'. The PCR fragments and the pGCFU plasmid were digested with Age I and then ligated with T4 DNA ligase to produce pGC-FU-FAM3A. To generate the recombinant Lentivirus LV- FAM3A, 293T cells were co-transfected with of the pGC-FU plasmid $(20 \mu \mathrm{g})$ with a cDNA encoding FAM3A, pHelper1.0 plasmid $(15 \mu \mathrm{g})$ and pHelper 2.0 plasmid $(10 \mu \mathrm{g})$ by using Lipofectamine $2000(100 \mu \mathrm{l})$. After 48 hours, supernatant was harvested and the viral titer was calculated by transducing $293 \mathrm{~T}$ cells. As a control, we also generated a control lentiviral vector that expresses GFP alone (LV-Control).

Flow cytometry

HT22 cells were harvested $24 \mathrm{~h}$ after exposure to $\mathrm{H}_{2} \mathrm{O}_{2}$, washed with ice-cold $\mathrm{Ca}^{2+}$ free PBS, and resuspended in binding buffer (10 mM HEPES, pH 7.4, $140 \mathrm{mM} \mathrm{NaCl}, 1 \mathrm{mM} \mathrm{MgCl}, 5 \mathrm{mM} \mathrm{KCl}$, and $2.5 \mathrm{mM} \mathrm{CaCl}_{2}$ ). Cell suspension was then incubated in $0.5 \mu \mathrm{g} / \mathrm{ml} \mathrm{FITC-conjugated} \mathrm{annexin} \mathrm{V} \mathrm{(AV)} \mathrm{at} \mathrm{room} \mathrm{temperature} \mathrm{in}$ darkness for $15 \mathrm{~min}$. Cellular DNA was stained by addition of $5 \mu \mathrm{l}$ of PI ( $50 \mu \mathrm{g} / \mathrm{ml}$ ) at room temperature for $5 \mathrm{~min}$, and the cells were analyzed by FACScan analysis with Cellquest software.

\section{Quantification of cytochrome c release}

Cytochrome c release was assessed after subcellular fraction preparation. HT22 cells were lysed and centrifuged for $10 \mathrm{~min}$ at $750 \mathrm{~g}$ at $4^{\circ} \mathrm{C}$, and the pellets containing the nuclei and unbroken cells were discarded. The supernatant was then centrifuged at $15000 \mathrm{~g}$ for $15 \mathrm{~min}$. The resulting supernatant was removed and used as the cytosolic fraction. The pellet fraction containing mitochondria was further incubated with PBS containing $0.5 \%$ Trition X-100 for $10 \mathrm{~min}$ at $4^{\circ} \mathrm{C}$. After centrifugation at $16000 \mathrm{~g}$ for 10 min, the supernatant was collected as mitochondrial fraction. The levels of cytochrome c in cytosolic and mitochondrial fractions were measured using the Quantikine M Cytochrome C Immunoassay kit obtained from R\&D Systems (Minneapolis, MN, USA). Data were expressed as ng/mg protein.

\section{Measurement of ROS generation}

Intracellular ROS were evaluated by the probe $2^{\prime}, 7^{\prime}$-dichlorofluorescin diacetate (DCFH-DA, Sigma). HT2 2 cells were incubated with $50 \mu \mathrm{g} / \mathrm{ml} \mathrm{DCFH-DA} \mathrm{for} 1 \mathrm{~h}$ at $37^{\circ} \mathrm{C}$ in the dark and then re-suspended in PBS. Fluorescence was read using an excitation wavelength of $480 \mathrm{~nm}$ and an emission wavelength of 530 $\mathrm{nm}$ with a fluorescence plate reader.

\section{Measurement of ATP synthesis}

Isolated mitochondria were utilized to measure ATP synthesis with a luciferase/ luciferin-based system as described previously [15]. $30 \mu \mathrm{g}$ of mitochondria enriched pellets were resuspended in $100 \mu \mathrm{l}$ of buffer A (150 mM KCl, $25 \mathrm{mM}$ Tris- $\mathrm{HCl}, 2 \mathrm{mM}$ potassium phosphate, $0.1 \mathrm{mM} \mathrm{MgCl}$, pH 7.4) with $0.1 \%$ BSA, $1 \mathrm{mM}$ malate, $1 \mathrm{mM}$ glutamate and buffer B (containing $0.8 \mathrm{mM}$ luciferin and $20 \mathrm{mg} / \mathrm{ml}$ luciferase in $0.5 \mathrm{M}$ Tris-acetate, $\mathrm{pH}$ 7.75). The reaction was initiated by addition of $0.1 \mathrm{mM}$ ADP and monitored for $5 \mathrm{~min}$ using a microplate reader.

\section{Measurement of lipid peroxidation}

Malonyldialdehyde (MDA) and 4-hydroxynonenal (4-HNE), two index of lipid peroxidation, were determined by using assay kits from Cell Biolabs and strictly following the manufacturer's instruction. The absorbance of the samples was measured by a microplate (ELISA) reader. 


\section{Cellular Physiology Cell Physiol Biochem 2015;37:1431-1441

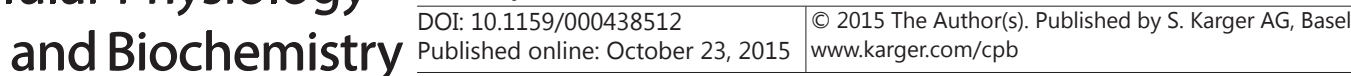 Song/Gou/Zhang: FAM3A Protects $\mathrm{HT}_{12}$ Cells Against $\mathrm{H}_{2} \mathrm{O}_{2}$ Injury}

Western blot analysis

Equivalent amounts of total protein ( $40 \mu \mathrm{g}$ per lane) were loaded and separated by $10 \%$ SDS-PAGE gels, and transferred to polyvinylidene difluoride (PVDF) membranes. Immunoblot was performed and the membrane was developed with ECL. The amount of protein was determined using software Image J with normalization to the control value.

\section{Statistical analysis}

Statistical analysis was performed using SPSS 16.0, a statistical software package. Statistical evaluation of the data was performed by $t$-test or one-way analysis of variance (ANOVA) followed by Bonferroni's multiple comparisons.

\section{Results}

Expression of FAM3A following $\mathrm{H}_{2} \mathrm{O}_{2}$-induced injury in $\mathrm{HT} 22$ cells

HT22 cells were incubated in the presence of $\mathrm{H}_{2} \mathrm{O}_{2}$ at different concentrations $(10,50,100$, $500 \mu \mathrm{M}$ or $1 \mathrm{mM}$ ) for $24 \mathrm{~h}$, and the results of cell viability (Fig. 1A) and LDH release (Fig. 1B)

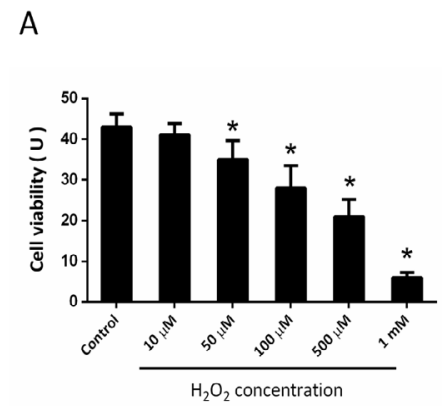

B

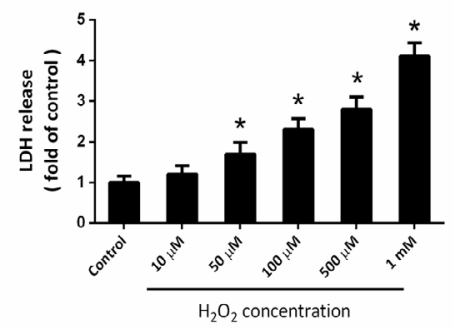

C

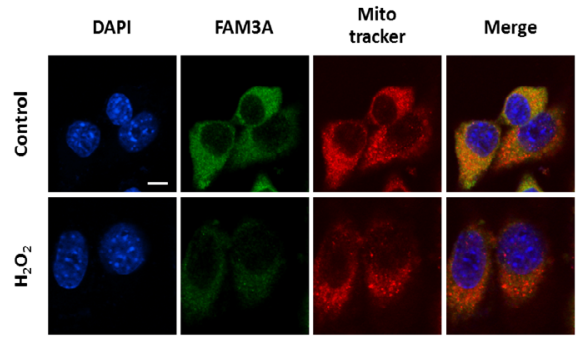

$\mathrm{E}$
D
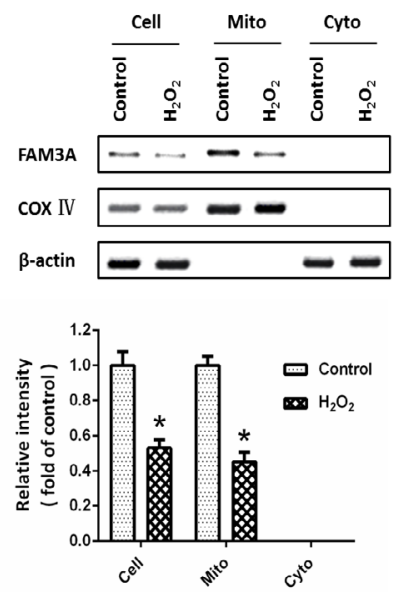
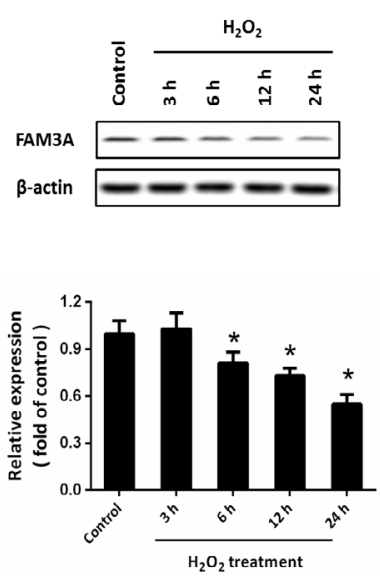

Fig. 1. Expression of FAM3A following $\mathrm{H}_{2} \mathrm{O}_{2}$-induced injury in $\mathrm{HT} 22$ cells. $\mathrm{HT} 22$ cells were treated with $\mathrm{H}_{2} \mathrm{O}_{2}$ at different concentrations for $24 \mathrm{~h}$, and cell viability (A) and LDH release (B) were assayed. (C) HT22 cells were treated with $500 \mu \mathrm{M} \mathrm{H}_{2} \mathrm{O}_{2}$, and the distribution of FAM3A was shown as immunofluorescence staining for FAM3A (green), mitochondria (red) and DAPI (nuclei). Scale bar: $10 \mu \mathrm{m}$. The expression of FAM3A in mitochondrial and cytosolic fractions was detected by western blot (D). The expression of FAM3A at different time points after $\mathrm{H}_{2} \mathrm{O}_{2}$ treatment was detected by western blot (E). Data are shown as mean \pm SEM $(\mathrm{n}=5) .{ }^{*} p<0.05$ vs. Control. 


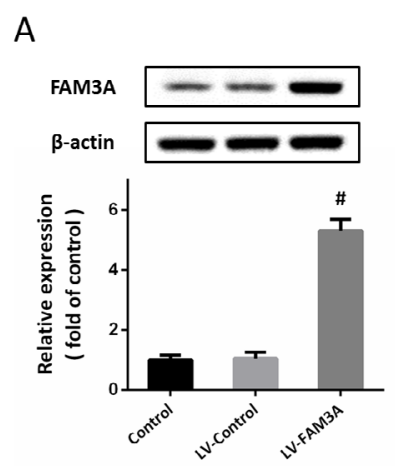

\section{B}

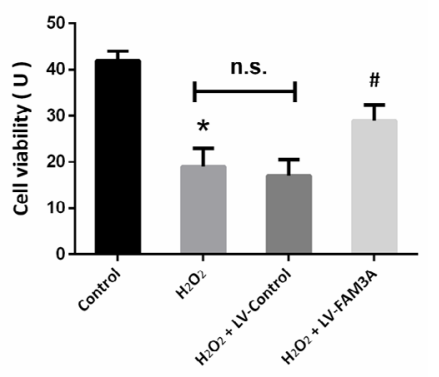

C

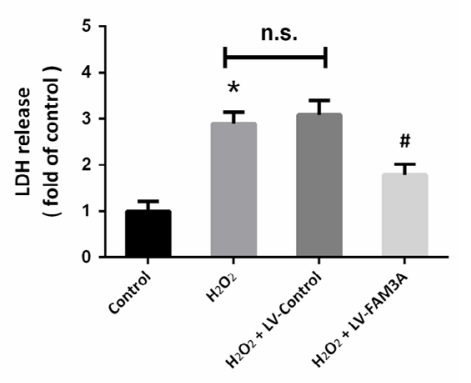

D
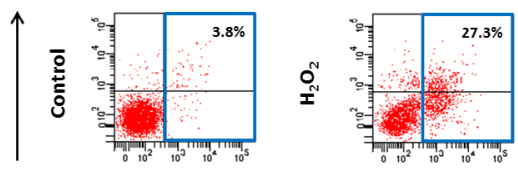

$\bar{a}$

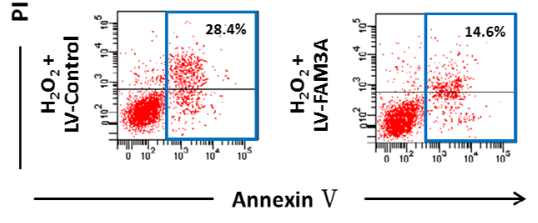

E

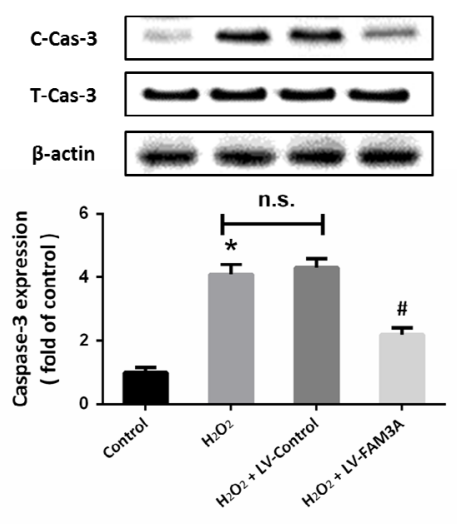

G
$\mathrm{F}$

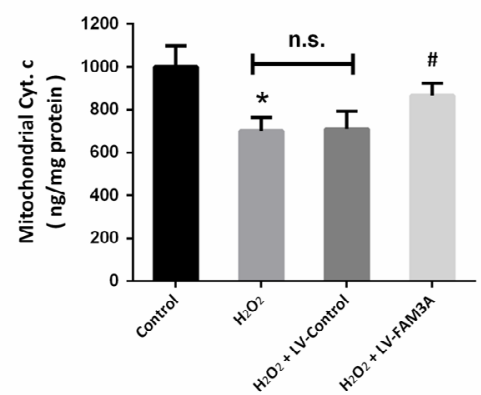

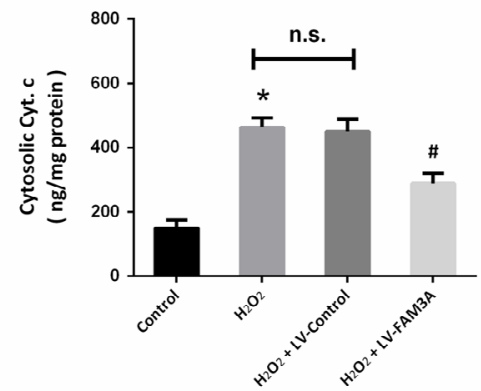

Fig. 2. Overexpression of FAM3A attenuates $\mathrm{H}_{2} \mathrm{O}_{2}$-induced toxicity. $\mathrm{HT} 22$ cells were transfected with lentivirus expressed FAM3A (LV-FAM3A) or control lentivirus (LV-Control) for 72 hours, and the expression of FAM3A was detected by western blot (A). After lentivirus transfection, HT22 cells were treated with 500 $\mu \mathrm{M} \mathrm{H}_{2} \mathrm{O}_{2}$ for $24 \mathrm{~h}$. The cell viability (B) and LDH release (C) were assayed, and the apoptotic cell death was detected by flow cytometry (D). The expression of cleaved caspase-3 (C-Cas-3) was detected by western blot (E). The cytochrome c content in mitochondrial (F) and cytosolic fractions (G) was measured. Data are shown as mean \pm SEM (n=5). ${ }^{*} p<0.05$ vs. Control. ${ }^{\#} p<0.05$ vs. LV-Control. n.s., not statistically significant.

showed that $\mathrm{H}_{2} \mathrm{O}_{2}$ induced dose-dependent cytotoxicity in $\mathrm{HT} 22$ cells. Because $500 \mu \mathrm{M} \mathrm{H}_{2} \mathrm{O}_{2}$ caused nearly half of the cells to die, this concentration was used in the following experiments. After treatment with $500 \mu \mathrm{M} \mathrm{H}_{2} \mathrm{O}_{2}$ for $24 \mathrm{~h}$, the results of fluorescence staining showed that the expression of FAM3A in $\mathrm{H}_{2} \mathrm{O}_{2}$ treated cells was significantly reduced as compared with control group, but the distribution of FAM3A was unaffected (Fig. 1C). To confirm the expression of FAM3A in the mitochondria, we also detected the expression of FAM3A in mitochondrial and cytosolic fractions (Fig. 1D). The results showed that the expression of FAM3A in mitochondrial and total cell homogenates was decreased after $\mathrm{H}_{2} \mathrm{O}_{2}$ exposure, 
Fig. 3. Overexpression of FAM3A reduces $\mathrm{H}_{2} \mathrm{O}_{2}$-induced oxidative stress. HT22 cells were transfected with LV-FAM3A or LV-Control for $72 \mathrm{~h}$, and treated with 500 $\mu \mathrm{M} \mathrm{H}_{2} \mathrm{O}_{2}$. Intracellular ROS generation was shown as immunofluorescence staining (A) for DCF (green) and DAPI (nuclei), and relative ROS levels were calculated (B) Scale bar: $100 \mu \mathrm{m}$. The ATP content (C) and lipid peroxidation (D, E) were assayed. Data are shown as mean \pm SEM $(n=5)$. ${ }^{*} p<0.05$ vs. Control. ${ }^{\#} p<0.05$ vs. LV-Control.

whereas no expression of FAM3A was detected in cytosolic fractions. As shown in Fig. 1E, $\mathrm{H}_{2} \mathrm{O}_{2}$ treatment induced a decrease in FAM3A expression in a timedependent manner in HT22 cells.

Overexpression of FAM3A attenuates $\mathrm{H}_{2} \mathrm{O}_{2}$-induced toxicity

To investigate the effect of FAM3A on $\mathrm{H}_{2} \mathrm{O}_{2}$-induced cytotoxicity, HT22 cells were transfected with lentivirus expressed FAM3A (LV-FAM3A) and control lentivirus (LV-Control). Immunoblot analysis indicated that exogenous FAM3A was expressed in HT22 cells by transfection with LV-FAM3A, whereas LV-Control had no

\section{A}
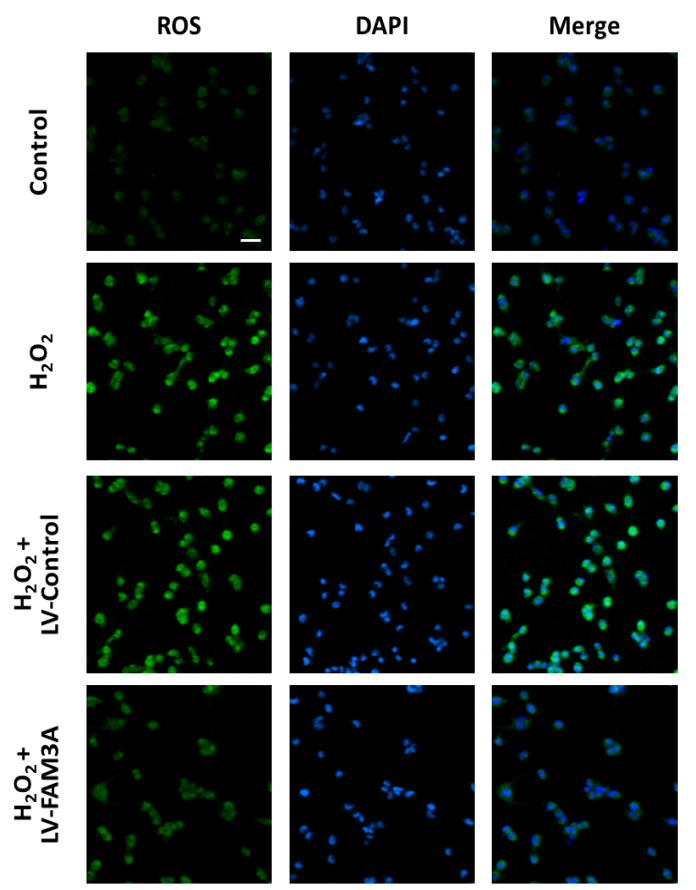

B

C
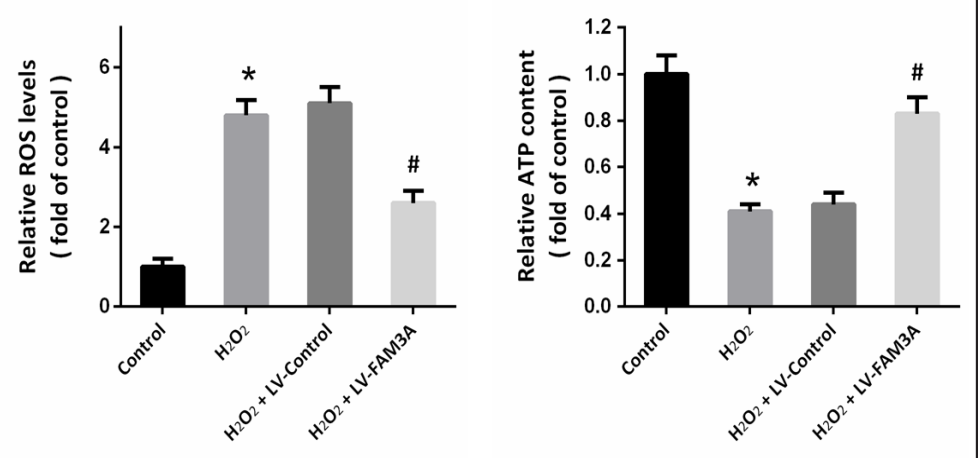

D

E
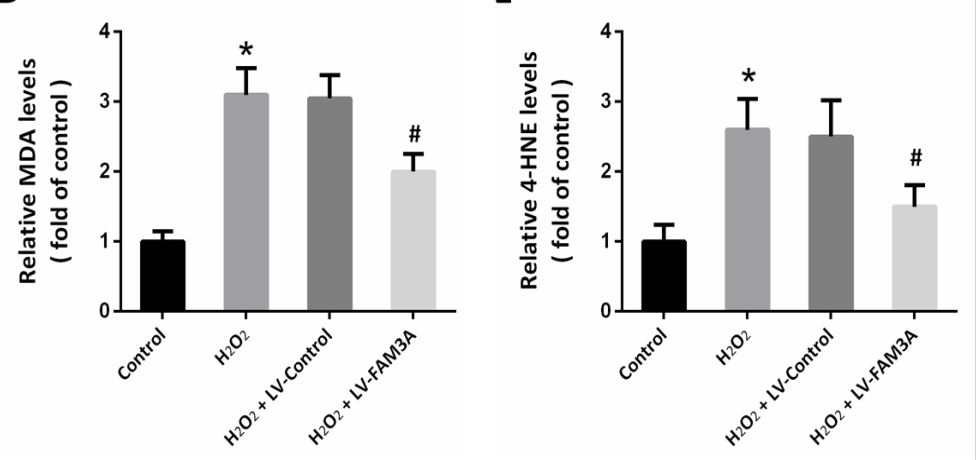

such effect (Fig. 2A). Overexpression of FAM3A significantly increased the cell viability, but decreased LDH release after $\mathrm{H}_{2} \mathrm{O}_{2}$ exposure (Fig. 2B and 2C). In addition, LV-FAM3A transfection reduced the number of $\mathrm{AV}^{+} / \mathrm{PI}^{+}$and $\mathrm{AV}^{+} / \mathrm{PI}^{-}$cells as measured by flow cytometry (Fig. 2D), and also decreased the cleavage of caspase- 3 in $\mathrm{H}_{2} \mathrm{O}_{2}$ treated cells (Fig. 2E), suggesting the anti-apoptotic activity of FAM3A. As shown in Fig. $2 \mathrm{~F}$, mitochondrial cytochrome c release induced by $\mathrm{H}_{2} \mathrm{O}_{2}$, as evidenced by a decrease in mitochondrial cytochrome c content, was KARGER 


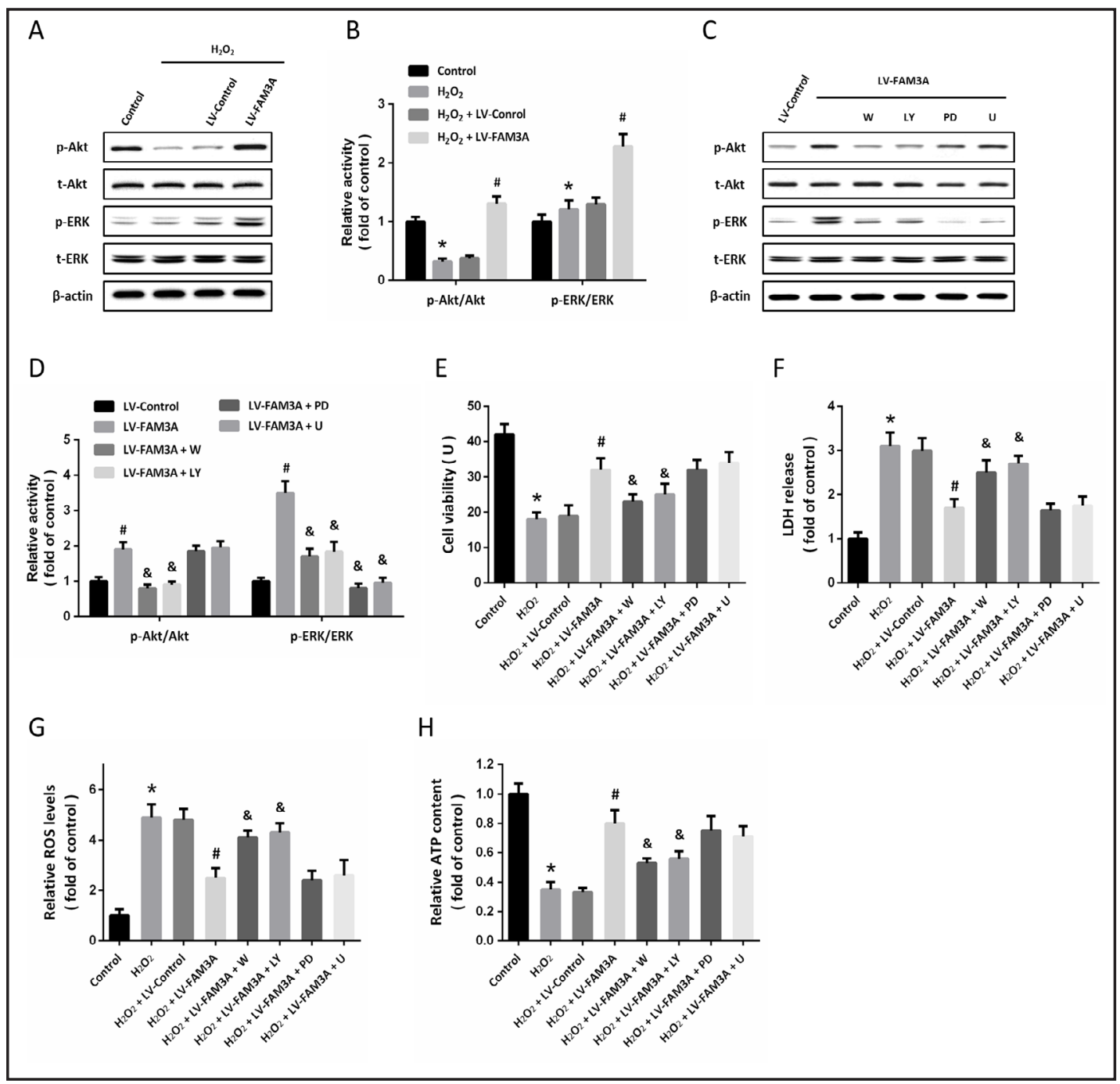

Fig. 4. Involvement of PI3K/Akt pathway in FAM3A-induced protection. HT22 cells were transfected with LV-FAM3A or LV-Control for $72 \mathrm{~h}$, and treated with $500 \mathrm{\mu M} \mathrm{H}_{2} \mathrm{O}_{2}$. The expression of p-Akt, t-Akt, p-ERK and t-ERK were detected by western blot (A) and calculated (B). After transfection with LV-FAM3A and LV-Control, HT22 cells were treated with wortmannin (W, $1 \mu \mathrm{M})$ or LY294002 (LY, $10 \mu \mathrm{M})$, and PD98059 (PD, 20 $\mu \mathrm{M})$ or U0126 (U, $2 \mu \mathrm{M})$, and the expression of p-Akt, t-Akt, p-ERK and t-ERK were detected by western blot (C) and calculated (D). After letivirus transfection and inhibitors treatment, HT22 cells were treated with $500 \mathrm{M} \mathrm{H}_{2} \mathrm{O}_{2}$. The cell viability (E), LDH release (F), ROS generation (G) and ATP content (H) were measured. Data are shown as mean \pm SEM $(\mathrm{n}=5) .{ }^{*} p<0.05$ vs. Control. ${ }^{\sharp} p<0.05$ vs. LV-Control. ${ }^{\circledR} p<0.05$ vs. LV-FAM3A.

partially prevented by FAM3A overexpression. In consistent, the $\mathrm{H}_{2} \mathrm{O}_{2}$-induced increase in cytosolic cytochrome c content was decreased by FAM3A overexpression (Fig. 2G).

Overexpression of FAM3A reduces $\mathrm{H}_{2} \mathrm{O}_{2}$-induced oxidative stress

To determine whether FAM3A affects the intracellular ROS production, HT22 cells were transfected with LV-FAM3A or LV-Control and exposure to $\mathrm{H}_{2} \mathrm{O}_{2}$. As shown in Fig. 3A, the intracellular ROS generation was measured by DCFDA-based fluorescence staining analysis. ROS production induced by $\mathrm{H}_{2} \mathrm{O}_{2}$ was reduced after transfection with LV-FAM3A, but was not decreased by transfection with LV-Control (Fig. 3B). FAM3A overexpression also preserved ATP generation after $\mathrm{H}_{2} \mathrm{O}_{2}$ treatment (Fig. 3C). Moreover, we also detected lipid peroxidation by measuring MDA and 4-HNE content. The results showed that $\mathrm{H}_{2} \mathrm{O}_{2}$ treatment significantly 


\section{Cellular Physiology Cell Physiol Biochem 2015;37:1431-1441

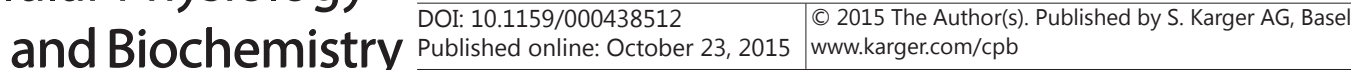 \\ Song/Gou/Zhang: FAM3A Protects $\mathrm{HT} 12$ Cells Against $\mathrm{H}_{2} \mathrm{O}_{2}$ Injury}

increased the production of MDA and 4-HNE, which were both partially reversed by FAM3A overexpression (Fig. 3D and 3E).

Involvement of PI3K/Akt pathway in FAM3A-induced protection

To investigate the potential molecular mechanism underlying FAM3A induced protection, western blot was performed to detect the activation of Akt and ERK in HT22 cells (Fig. 4A). The results showed that FAM3A overexpression significantly increased the expression of p-Akt and p-ERK, but had no effect on t-Akt and t-ERK expression (Fig. 4B). To further determine the involvement of Akt and ERK pathways in FAM3A induced protection, as shown in Fig. 4C, HT22 cells were treated with wortmannin (W, $1 \mu \mathrm{M})$ or LY294002 (LY, $10 \mu \mathrm{M}$ ), and PD98059 (PD, $20 \mu \mathrm{M}$ ) or U0126 (U, $2 \mu \mathrm{M})$. Treatment with W and LY selectively inhibited Akt activity, and ERK phosphorylation was suppressed by PD and U (Fig. 4D). Intriguingly, increased expression of p-ERK induced by FAM3A in HT22 cells was also markedly decreased by $\mathrm{W}$ and LY, indicating that the increased activation of MEK/ ERK induced by FAM3A might be the results indirectly from its effect on PI3K/Akt pathway. Furthermore, the results of cell viability (Fig. 4E), LDH release (Fig. 4F), intracellular ROS generation (Fig. 4G) and ATP measurement (Fig. 4H) in the presence of inhibitors showed that FAM3A induced protection agains $\mathrm{H}_{2} \mathrm{O}_{2}$ treatment was partially prevented by inhibition of PI3K/Akt pathway, but not by inhibition of MEK/ERK pathway.

\section{Discussion}

Among four members of FAM3 family proteins, the role of FAM3B in glucose and lipid metabolism has been intensively investigated $[9,16]$. However, the biological function of FAM3A, especially in central nervous system, remains poorly understood. In the present study, we found that FAM3A expression was reduced in HT22 hippocampal neuronal cells after $\mathrm{H}_{2} \mathrm{O}_{2}$ exposure. For the first time, we demonstrated that neuronal overexpression of FAM3A exerted protective effects against ROS related oxidative stress. These findings indicate that deregulated FAM3A expression might be an ideal therapeutic target for the treatment of neurological disorders where neuronal oxidative stress contributes to the pathology.

Regarding possible mechanisms underlying the protective effects observed here, we found that FAM3A overexpression significantly reduced apoptosis as measured by flow cytometry. $\mathrm{H}_{2} \mathrm{O}_{2}$ and other ROS have been found to induce many types of DNA damage, such as DNA breaks, base and sugar modifications, DNA-protein crosslinks, depurination and depyrimidination [17]. They also disrupt the membrane integrity of mitochondria and increase the formation of mitochondrial transition pores, which in turn promotes the release of pro-apoptotic factors and aggravates NDA damage [18]. The roles of FAM3 family proteins in cell survival and apoptosis are not fully understood. Previous studies showed that recombinant FAM3B treatment or adenovirus mediated FAM3B overexpression induced betaTC3 cell and mouse islet apoptosis $[16,19]$. However, a recent report indicated that FAM3B was essential for cell survival and knockdown of FAM3B triggered apoptosis through p53 dependent pathway [20]. These opposite results might be explained by the different tissues and in vitro models used. Our results of caspase- 3 activation and cytochrome c release measurement indicated that FAM3A exerts anti-apoptotic activity in neuronal cells. Therefore, the FAM3 family proteins might play different roles in cell survival and apoptosis in various tissue and cell types, which warrant further investigations.

Previous studies using northern analysis indicated that the FAM3A mRNA was ubiquitously expressed in almost all tissues of humans and rodents [9]. Our results confirmed the expression of FAM3A protein in neuronal HT22 cells. In addition, we observed that FAM3A is subcellularly located mainly in the mitochondria, which was consistent with previous findings in liver and vascular smooth muscle cells $[14,21]$. Thus, we speculated that the role of FAM3A under oxidative stress conditions might be related to the regulation of mitochondrial energy metabolism and ROS generation. The results of DCF fluorescence 


\section{Cellular Physiology Cell Physiol Biochem 2015;37:1431-1441

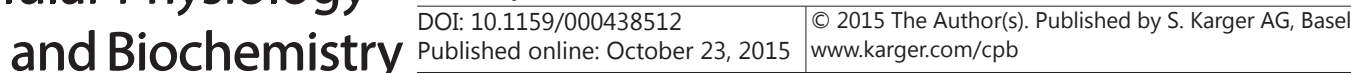 \\ Song/Gou/Zhang: FAM3A Protects $\mathrm{HT} 12$ Cells Against $\mathrm{H}_{2} \mathrm{O}_{2}$ Injury}

staining and measurement of MDA and 4-HNE indicated that overexpression of FAM3A markedly attenuated ROS generation and lipid peroxidation, suggesting that suppressed oxidative stress products may be responsible for metabolic improvement after FAM3A overexpression. ROS are mainly produced by mitochondria, and oxidative stress-induced ROS production contributes to neuronal death by oxidation of many important lipids, eventually leading to aggravated mitochondrial dysfunction $[22,23]$. We found that overexpression of FAM3A also preserved the intracellular ATP generation after $\mathrm{H}_{2} \mathrm{O}_{2}$ exposure, which further confirmed the role of FAM3A in mitochondrial function regulation under oxidative stress conditions.

In response to oxidative stress, various signal transduction pathways are triggered, among which PI3K/Akt and MEK/ERK are two important cascades. The serine and threonine protein kinase, which is a critical downstream target of PI3K, plays a key role in regulating cellular functions and results from extracellular stimulus [24]. Equally, as one member of mitogen-activated protein kinases (MAPKs) family, ERK can transduce a large number of extracellular information into intracellular responses [25]. Some authors have suggested that FAM3A elicit signaling such as Akt and ERK phosphorylation in liver and vascular smooth muscle cells [14, 21]. Consistently, our results showed that both p-Akt and p-ERK expression were up-regulated by FAM3A overexpression, suggesting the possible involvement of these cascades in FAM3A induced protection. Akt has been known as an endogenous protective factor against cell death in many kinds of insults, and it can inhibit apoptosis in many ways, both upstream and downstream of mitochondrial perturbation [26]. In contrast, the role of ERK in cell death was disputable. Despite the volume of evidence supporting the p-ERK elevation as detrimental effects that were essential for oxidative stress and inflammationrelated cell death, numerous studies demonstrated that ERK activation contributed to protective effects of many neuroprotectants $[27,28]$. In our study, overexpression of FAM3Ainduced protection against cell death and oxidative stress was partially prevented by both wortmannin and LY294002, but not by PD98059 and U0126. Therefore, it is reasonable to assume that the activation of PI3K/Akt, but not MEK/ERK, mediates FAM3A-induced protection against $\mathrm{H}_{2} \mathrm{O}_{2}$-induced cytotoxicity.

It is well known that signaling pathways can crosstalk with each other wherein one pathway can signal to either enhance or suppress signaling by another [29-31]. Whether cross-inhibition or cross-activation occurs between these pathways is dependent on different conditions. The interaction of PI3K/Akt with MEK/ERK has shown crosstalk on multiple levels. Akt was shown to positively regulate Raf phosphorylation and ERK activation in prostate cancer cells in response to androgen depletion [32]. A previous study indicated that Gi-coupled receptor- and G $\beta \gamma$-stimulated ERK activation is attenuated by the PI3K inhibitors wortmannin and LY294002 or by overexpression of a dominant negative mutant of the p85 subunit of PI3K [33]. In our study, both wortmannin and LY294002 were demonstrated to inhibit not only the activation of Akt, but also ERK, which means that the activation of ERK in our in vitro conditions is dependent on the activity of PI3K/Akt signaling pathway at the level of PI3K. However, PD98059 and U0126 inhibited the activation of ERK, with no effect on Akt activity, suggesting that FAM3A induced activation of Akt was not dependent on MEK/ERK pathway. In addition, treatment with PD98059 and U0126 had no effects on FAM3A induced protection against $\mathrm{H}_{2} \mathrm{O}_{2}$ exposure in HT22 cells. Intriguingly, our results showed that ERK1/2 inhibition in $\mathrm{H}_{2} \mathrm{O}_{2}$ + LYFAM3A +PD or $\mathrm{U}$ treated cells increases the phosphorylation levels of Akt to levels that are equal to that obtained with LV-FAM3A $+\mathrm{H}_{2} \mathrm{O}_{2}$ treated cells. It might be ruled out that this increase in Akt with ERK inhibition contributes to the protection against $\mathrm{H}_{2} \mathrm{O}_{2}$ toxicity in that the levels of cell viability, ROS and ATP with ERK inhibition are equal to that of the LV-FAM3A control. However, significant inhibition on FAM3A-induced protection was detected after treatment Akt inhibitors. Thus, whether ERK inhibition-induced regulation on Akt activity was involved in FAM3A-induced protection needs to be further determined. From our results, we think that the involvement FAM3A in moderating the PI3K/Akt pathway could occur at the level upstream of MEK/ERK. The exact mechanisms need further investigation in other neuronal cells and also in vivo conditions. 


\section{Cellular Physiology Cell Physiol Biochem 2015;37:1431-1441 and Biochemistry Published online: October 23, 2015 le $\begin{aligned} & \text { C } 2015 \text { The Author(s). Published by S. Karger AG, Basel } \\ & \text { www.karger.com/cpb }\end{aligned}$ \\ Song/Gou/Zhang: FAM3A Protects $\mathrm{HT} 12$ Cells Against $\mathrm{H}_{2} \mathrm{O}_{2}$ Injury}

Thus, these observations provided a new element to the crosstalk between PI3K/Akt and MEK/ERK pathways under oxidative stress conditions.

\section{Conclusions}

In summary, FAM3A is expressed in HT22 cells, where it affects ROS generation and mitochondrial ATP production, and inhibits apoptotic cell death via a PI3K/Akt mediated, but MEK/ERK independent, signaling pathway. Overexpression of FAM3A is beneficial for preventing oxidative stress induced by $\mathrm{H}_{2} \mathrm{O}_{2}$ in neuronal cells.

\section{Acknowledgements}

This work was financially supported by Science and Technology Project Foundation of Shaanxi (No. 2014K11-03-09-08). The authors would like to thank Dr. Terry Chen for his technical support for the experiments and the preparation of the manuscript.

\section{Disclosure Statement}

The authors report no conflicts of interest.

\section{References}

1 Devasagayam TP, Tilak JC, Boloor KK, Sane KS, Ghaskadbi SS, Lele RD: Free radicals and antioxidants in human health: current status and future prospects. J Assoc Physicians India 2004;52:794-804.

2 Rao KS: Free radical induced oxidative damage to DNA: relation to brain aging and neurological disorders. Indian J Biochem Biophys 2009;46:9-15.

3 Wang R, Liu YY, Liu XY, Jia SW, Zhao J, Cui D, Wang L: Resveratrol protects neurons and the myocardium by reducing oxidative stress and ameliorating mitochondria damage in a cerebral ischemia rat model. Cell Physiol Biochem 2014;34:854-864.

4 Zhang W, Qian C, Li SQ: Protective effect of SGK1 in rat hippocampal neurons subjected to ischemia reperfusion. Cell Physiol Biochem 2014;34:299-312.

5 Annunziato L, Amoroso S, Pannaccione A, Cataldi M, Pignataro G, D'Alessio A, Sirabella R, Secondo A, Sibaud L, Di Renzo GF: Apoptosis induced in neuronal cells by oxidative stress: role played by caspases and intracellular calcium ions. Toxicol Lett 2003;139:125-133.

6 Chen T, Fei F, Jiang XF, Zhang L, Qu Y, Huo K, Fei Z: Down-regulation of Homer1b/c attenuates glutamatemediated excitotoxicity through endoplasmic reticulum and mitochondria pathways in rat cortical neurons. Free Radic Biol Med 2012;52:208-217.

7 Xu H, Luo P, Zhao Y, Zhao M, Yang Y, Chen T, Huo K, Han H, Fei Z: Iduna protects HT22 cells from hydrogen peroxide-induced oxidative stress through interfering poly(ADP-ribose) polymerase-1-induced cell death (parthanatos). Cell Signal 2013;25:1018-1026.

8 Dai SH, Chen T, Wang YH, Zhu J, Luo P, Rao W, Yang YF, Fei Z, Jiang XF: Sirt3 attenuates hydrogen peroxideinduced oxidative stress through the preservation of mitochondrial function in HT22 cells. Int J Mol Med 2014;34:1159-1168.

9 Zhu Y, Xu G, Patel A, McLaughlin MM, Silverman C, Knecht K, Sweitzer S, Li X, McDonnell P, Mirabile R, Zimmerman D, Boyce R, Tierney LA, Hu E, Livi GP, Wolf B, Abdel-Meguid SS, Rose GD, Aurora R, Hensley P, Briggs M, Young PR: Cloning, expression, and initial characterization of a novel cytokine-like gene family. Genomics 2002;80:144-150.

10 Yang J, Guan Y: Family with sequence similarity 3 gene family and nonalcoholic fatty liver disease. J Gastroenterol Hepatol 2013;28:105-111.

11 Yang J, Gao Z, Robert CE, Burkhardt BR, Gaweska H, Wagner A, Wu J, Greene SR, Young RA, Wolf BA: Structure-function studies of PANDER, an islet specific cytokine inducing cell death of insulin-secreting beta cells. Biochemistry 2005;44:11342-11352. 


\section{Cellular Physiology Cell Physiol Biochem 2015;37:1431-1441

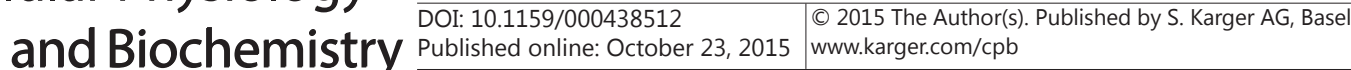 \\ Song/Gou/Zhang: FAM3A Protects HT12 Cells Against $\mathrm{H}_{2} \mathrm{O}_{2}$ Injury}

12 Wang C, Burkhardt BR, Guan Y, Yang J: Role of pancreatic-derived factor in type 2 diabetes: evidence from pancreatic beta cells and liver. Nutr Rev 2012;70:100-106.

13 Zhou Y, Jia S, Wang C, Chen Z, Chi Y, Li J, Xu G, Guan Y, Yang J: FAM3A is a target gene of peroxisome proliferator-activated receptor gamma. Biochim Biophys Acta 2013;1830:4160-4170.

14 Wang C, Chi Y, Li J, Miao Y, Li S, Su W, Jia S, Chen Z, Du S, Zhang X, Zhou Y, Wu W, Zhu M, Wang Z, Yang H, Xu G, Wang S, Yang J, Guan Y: FAM3A activates PI3K p110alpha/Akt signaling to ameliorate hepatic gluconeogenesis and lipogenesis. Hepatology 2014;59:1779-1790.

15 Parone PA, Da Cruz S, Han JS, McAlonis-Downes M, Vetto AP, Lee SK, Tseng E, Cleveland DW: Enhancing mitochondrial calcium buffering capacity reduces aggregation of misfolded SOD1 and motor neuron cell death without extending survival in mouse models of inherited amyotrophic lateral sclerosis. J Neurosci 2013;33:4657-4671.

16 Cao X, Yang J, Burkhardt BR, Gao Z, Wong RK, Greene SR, Wu J, Wolf BA: Effects of overexpression of pancreatic derived factor (FAM3B) in isolated mouse islets and insulin-secreting betaTC3 cells. Am J Physiol Endocrinol Metab 2005;289:E543-550.

17 Shackelford RE, Kaufmann WK, Paules RS: Oxidative stress and cell cycle checkpoint function. Free Radic Biol Med 2000;28:1387-1404.

18 Li RC, Morris MW, Lee SK, Pouranfar F, Wang Y, Gozal D: Neuroglobin protects PC12 cells against oxidative stress. Brain Res 2008;1190:159-166.

19 Cao X, Gao Z, Robert CE, Greene S, Xu G, Xu W, Bell E, Campbell D, Zhu Y, Young R, Trucco M, Markmann JF, Naji A, Wolf BA: Pancreatic-derived factor (FAM3B), a novel islet cytokine, induces apoptosis of insulinsecreting beta-cells. Diabetes 2003;52:2296-2303.

20 Mou H, Li Z, Yao P, Zhuo S, Luan W, Deng B, Qian L, Yang M, Mei H, Le Y: Knockdown of FAM3B triggers cell apoptosis through p53-dependent pathway. Int J Biochem Cell Biol 2013;45:684-691.

21 Jia S, Chen Z, Li J, Chi Y, Wang J, Li S, Luo Y, Geng B, Wang C, Cui Q, Guan Y, Yang J: FAM3A promotes vascular smooth muscle cell proliferation and migration and exacerbates neointima formation in rat artery after balloon injury. J Mol Cell Cardiol 2014;74:173-182.

22 Avery SV: Molecular targets of oxidative stress. Biochem J 2011;434:201-210.

23 Dai SH, Chen T, Wang YH, Zhu J, Luo P, Rao W, Yang YF, Fei Z, Jiang XF: Sirt3 protects cortical neurons against oxidative stress via regulating mitochondrial Ca2+ and mitochondrial biogenesis. Int J Mol Sci 2014;15:14591-14609.

24 Fukunaga K, Kawano T: Akt is a molecular target for signal transduction therapy in brain ischemic insult. J Pharmacol Sci 2003;92:317-327.

25 Brami-Cherrier K, Roze E, Girault JA, Betuing S, Caboche J: Role of the ERK/MSK1 signalling pathway in chromatin remodelling and brain responses to drugs of abuse. J Neurochem 2009;108:1323-1335.

26 Yang L, Guo W, Zhang Q Li H, Liu X, Yang Y, Zuo J, Liu W: Crosstalk between Raf/MEK/ERK and PI3K/AKT in suppression of Bax conformational change by Grp75 under glucose deprivation conditions. J Mol Biol 2011;414:654-666.

27 Chen T, Zhang L, Qu Y, Huo K, Jiang X, Fei Z: The selective mGluR5 agonist CHPG protects against traumatic brain injury in vitro and in vivo via ERK and Akt pathway. Int J Mol Med 2012;29:630-636.

28 Chen T, Liu W, Chao X, Qu Y, Zhang L, Luo P, Xie K, Huo J, Fei Z: Neuroprotective effect of osthole against oxygen and glucose deprivation in rat cortical neurons: involvement of mitogen-activated protein kinase pathway. Neuroscience 2011;183:203-211.

29 Dent P: Crosstalk between ERK, AKT, and cell survival. Cancer Biol Ther 2014;15:245-246.

30 Chen T, Yang YF, Luo P, Liu W, Dai SH, Zheng XR, Fei Z, Jiang XF: Homer1 knockdown protects dopamine neurons through regulating calcium homeostasis in an in vitro model of Parkinson's disease. Cell Signal 2013;25:2863-2870.

31 Chen T, Zhu J, Zhang C, Huo K, Fei Z, Jiang XF: Protective effects of SKF-96365, a non-specific inhibitor of SOCE, against MPP+-induced cytotoxicity in PC12 cells: potential role of Homer1. PLoS One 2013;8:e55601.

32 Hong SK, Jeong JH, Chan AM, Park JI: AKT upregulates B-Raf Ser445 phosphorylation and ERK1/2 activation in prostate cancer cells in response to androgen depletion. Exp Cell Res 2013;319:1732-1743.

33 Hawes BE, Luttrell LM, van Biesen T, Lefkowitz RJ: Phosphatidylinositol 3-kinase is an early intermediate in the $\mathrm{G}$ beta gamma-mediated mitogen-activated protein kinase signaling pathway. J Biol Chem 1996;271:12133-12136. 